\title{
Cognitive Behavioural Therapy for Anxiety Disorders in Young Children: A Dutch Open Trial of the Fun FRIENDS Program
}

\author{
Malindi van der Mheen ${ }^{1}$, Jeroen S. Legerstee ${ }^{1}$, Gwendolyn C. Dieleman ${ }^{1}$, Manon H.J. Hillegers ${ }^{1}$ \\ and Elisabeth M.W.J. Utens ${ }^{1,2,3 *}$ \\ ${ }^{1}$ Department of Child and Adolescent Psychiatry/Psychology, Erasmus MC - Sophia Children's Hospital, Rotterdam, The \\ Netherlands, ${ }^{2}$ Research Institute of Child Development and Education, University of Amsterdam, Amsterdam, The \\ Netherlands and ${ }^{3}$ Academic Centre for Child and Adolescent Psychiatry the Bascule/Department of Child and Adolescent \\ Psychiatry, Academic Medical Centre, Amsterdam, The Netherlands \\ ${ }^{*}$ Corresponding author: Elisabeth Utens, Erasmus MC - Sophia Children's Hospital, Department of Child and Adolescent \\ Psychiatry/Psychology, KP building, KP-2865, Wytemaweg 8, 3015 CN Rotterdam, The Netherlands. \\ Email: e.utens@erasmusmc.nl
}

(Received 22 February 2019; revised 18 June 2019; accepted 2 September 2019; first published online 30 October 2019)

\begin{abstract}
Anxiety disorders in young children are highly prevalent and increase the risk of social, school, and familial problems, and also of psychiatric disorders in adolescence and adulthood. Nevertheless, effective interventions for this age group are lacking. One of the few available interventions is the Fun FRIENDS program. We examined whether young children with anxiety disorders showed less anxiety after participating in Fun FRIENDS. Twenty-eight clinically anxious children (4-8 years old) participated in the cognitive behavioural Fun FRIENDS program. The program consists of 12 weekly 1.5-hour sessions and was provided in groups of 3 to 5 children. At preintervention and direct postintervention, parents completed the Anxiety Disorders Interview Schedule for Children and Child Behavior Checklist. Clinically and statistically significant decreases were found in number of anxiety disorders, symptom interference, emotional and behavioural problems, internalising problems, and anxiety problems. The decrease in anxious/ depressed problems and externalising problems was not significant. Furthermore, higher preintervention anxiety levels predicted more treatment progress, whereas sex and age did not. The Dutch version of Fun FRIENDS is promising in treating anxiety disorders in young children. Randomised controlled trials are needed to draw definite conclusions on the effectiveness of Fun FRIENDS in a clinical setting.
\end{abstract}

Keywords: anxiety disorders; preschool child; cognitive therapy; behaviour therapy; Fun FRIENDS

Scientific interest in anxiety disorders in young children has increased in the past decade. Anxiety symptoms and diagnostic categories in young children resemble those in older children (Mian, Godoy, Briggs-Gowan, \& Carter, 2012). In young children, prevalence rates of anxiety disorders ranging from 9.4\% (Egger \& Angold, 2006) up to 22.2\% (Paulus, Backes, Sander, Weber, \& von Gontard, 2015) have been found. Unfortunately, anxiety disorders are often unrecognised in young children because anxious children are considered to be shy, cooperative and compliant (Albano, Chorpita, \& Barlow, 2003). If left unnoticed and untreated, this can have harmful consequences, as early-onset anxiety disorders can become chronic (Essau, Lewinsohn, Lim, Ho, \& Rohde, 2018; Essau, Lewinsohn, Olaya, \& Seeley, 2014). Research also shows that a diagnosis of an anxiety disorder in early childhood predicts anxiety and depression in adolescence, and significantly increases the risk

(C) The Author(s) 2019. This is an Open Access article, distributed under the terms of the Creative Commons Attribution licence (http://creativecommons.org/licenses/by/4.0/), which permits unrestricted re-use, distribution, and reproduction in any medium, provided the original work is properly cited. 
of having psychiatric disorders in adolescence and adulthood (Bienvenu \& Ginsburg, 2007; Bittner et al., 2007; Copeland et al., 2013; Copeland, Shanahan, Costello, \& Angold, 2009; Costello, Mustillo, Erkanli, Keeler, \& Angold, 2003; Essau et al., 2018; Moffitt et al., 2007). Moreover, childhood anxiety disorders are associated with social (de Lijster et al., 2018), school (de Lijster et al., 2018; Mychailyszyn, Mendez, \& Kendall, 2010), and familial (Towe-Goodman, Franz, Copeland, Angold, \& Egger, 2014) problems. Anxiety disorders have a significant impact on societal costs due to poorer academic outcomes, financial dependence and unemployment in adulthood (Barrett, Cooper, \& Teoh, 2014; Bodden, Dirksen, \& Bögels, 2008).

Considering these alarming outcomes, early intervention is urgently needed. Providing intervention at a young age has important advantages. First, anxious thoughts and behaviours may be easier to modify in younger children, as anxiety symptoms are likely to be less ingrained and neuroplasticity in young children is high (Hirshfeld-Becker \& Biederman, 2002). Second, intervening early in the lifespan can minimise the impact of anxiety symptoms on the development and future of the child (Connolly \& Bernstein, 2007; Donovan \& March, 2014; Fox et al., 2012; Hirshfeld-Becker \& Biederman, 2002)

Despite the serious need for an evidence-based intervention for anxious young children, only a few studies have been conducted into interventions for this age group (Anticich, Barrett, Silverman, Lacherez, \& Gillies, 2013; Fox et al., 2012; von Klitzing, Dohnert, Kroll, \& Grube, 2015; for a complete overview, see Fisak \& Barrett, 2019). An intervention that has been developed for 4- to 7-year-old children with anxiety disorders is the cognitive behavioural Fun FRIENDS program (Barrett, 2007b; Pahl \& Barrett, 2007). The Fun FRIENDS program is an adaptation for young children of the evidencebased FRIENDS for Life program (Barrett \& Turner, 2000), which was based on the Coping Cat program (Kendall, 1994). The Fun FRIENDS program aims to increase children's emotional resilience, social-emotional skills and coping skills, and to reduce emotional and behavioural problems. The program consists of 12 group sessions and is provided in a play-based manner, based on an experiential learning approach.

Until now, only two studies have examined the effectiveness of Fun FRIENDS delivered as a preventive program (Anticich et al., 2013; Pahl \& Barrett, 2010). In addition, three studies have studied the outcomes of Fun FRIENDS delivered as a treatment program for young children with clinical internalising symptoms or anxiety disorders (Barrett, Fisak, \& Cooper, 2015; Carlyle, 2014; Fisak, Gallegos-Guarjardo, Verreynne, \& Barrett, 2018).

Both prevention studies were randomised controlled trials in which Fun FRIENDS was delivered in a universal, classroom-based manner by psychology students or classroom teachers. In the first prevention study $(N=263$, mean age $=4.56, S D=0.51$; Pahl \& Barrett, 2010), both the Fun FRIENDS intervention group and the waitlist control group showed comparable improvements on parent reports of anxiety, behavioural inhibition, and social-emotional strength. Regarding teacher reports, however, the Fun FRIENDS intervention group showed greater improvements than the waitlist control group in behavioural inhibition and social-emotional strength, especially for girls. For ethical reasons, 12-month follow-up assessments were only completed for the intervention group. From preintervention to 12-month follow-up, the Fun FRIENDS intervention group showed improvements in anxiety and social-emotional strength, and for girls in behavioural inhibition. In the second prevention study $(N=488$, age range $4-7$ years, mean age $=5.42, S D=0.67$; Anticich et al., 2013), children who had participated in Fun FRIENDS showed greater improvements in behavioural and emotional strength, and behavioural inhibition than children from the active control group (cognitive behavioural 'You Can Do It' program; Ashdown \& Bernard, 2011) and waitlist control group.

As for Fun FRIENDS as a treatment program, the first study consisted of a pilot study $(N=6$, age range 4-7 years). This study suggested that Fun FRIENDS was effective in reducing anxiety of young children referred to a mental health service for anxiety symptoms (Carlyle, 2014). The second treatment study was an open trial that included young children $(N=31$, age range $5-7$, mean age $=5.68$, $S D=0.54$ ) who were diagnosed with one or more anxiety disorders (Barrett et al., 2015). From preintervention to immediate postintervention, significant improvements in anxiety symptoms, shyness, number of anxiety disorder diagnoses and resilience were found. These results were maintained at 
12-month follow-up. The third treatment study was also an open trial targeting young children $(N=$ 178 , age range $5-7$, mean age $=5.27, S D=0.93$ ) with internalising symptoms (Fisak et al., 2018). Their parents simultaneously received a resilience-building program (Barrett, 2012a, 2012b). For child outcomes, from preintervention to immediate postintervention, significant reductions in internalising symptoms and significant improvements in resilience were found.

Considering these promising outcomes, the Fun FRIENDS protocol was translated and adjusted for the Netherlands (Utens, 2011a, 2011b). The aim of the current study is to examine whether young children with anxiety disorders show fewer anxiety symptoms after participating in the Dutch version of the Fun FRIENDS program, and to identify predictors of treatment progress. We thereby aim to add to the limited available knowledge concerning evidence-based treatment for young children with anxiety disorders and to contribute to the cross-cultural knowledge regarding this innovative cognitive behavioural program. We hypothesised that anxiety symptoms and the number of anxiety diagnoses would decrease after participating in Fun FRIENDS.

\section{Methods}

\section{Participants}

Children who were 4-8 years old and met the Diagnostic and Statistical Manual of Mental Disorders (4th ed.; DSM-IV; American Psychiatric Association, 1994) diagnostic criteria for at least one anxiety disorder were eligible to participate in the Fun FRIENDS program. DSM- $I V$ anxiety disorder criteria were assessed based on the parent version of the Anxiety Disorders Interview Schedule for Children (ADIS-C; Silverman, Saavedra, \& Pina, 2001). All participants were referred to the Department of Child and Adolescent Psychiatry of the Erasmus Medical Center - Sophia Children's Hospital in Rotterdam between December 2008 and November 2013. Children with an IQ below 70 or a diagnosis of a posttraumatic stress disorder without a comorbid anxiety disorder were excluded from participation. In total, 28 children participated in the Fun FRIENDS program. Participant characteristics can be found in Table 1. As parental education is associated with persistence and severity of mental disorders (McLaughlin et al., 2011), we have presented maternal education levels. Participants' primary anxiety disorder diagnoses are shown in Table 2 and all anxiety disorder diagnoses are shown in Table 3.

\section{Procedure}

This retrospective open trial study was conducted using a one-group pretest-posttest design. All parents were asked to complete assessments as part of the routine intake procedure (preintervention) and directly after the Fun FRIENDS intervention (postintervention). As the Fun FRIENDS program was provided within the framework of regular treatment, assessments were completed as usual and data were analysed retrospectively, this study was not subject to the Dutch Medical Research Involving Human Subjects Act. The local research ethics committee was informed about the study and confirmed that full ethical approval of the study was not required. Participants were informed that collected data would be used anonymously in scientific research and that they could always opt out without any consequences for the treatment of their child.

\section{Treatment}

All children participated in the Dutch version of the Fun FRIENDS program (Barrett, 2007b; Utens, 2011b). The program was delivered to seven consecutive treatment groups. Five groups consisted of 4 children, one group of 5 children, and one group of 3 children $(n=28)$. The children received 12 weekly 1.5-hour sessions. On average, the program was delivered over a time period of 3.5 months. All sessions were led by two licensed, experienced psychologists. One of them received training from the developer of the Fun FRIENDS program. At each session, a master's student in psychology was present to make observations, take notes, and assist the psychologists. The content of each session 
Table 1. Participant characteristics.

\begin{tabular}{|c|c|c|c|}
\hline \multirow[b]{2}{*}{ Characteristic $(n=28)$} & \multicolumn{3}{|c|}{$N(\%)$ or $M(S D)$} \\
\hline & Total sample $(n=28)$ & ADIS-C completers $(n=22)$ & CBCL completers $(n=15)$ \\
\hline \multicolumn{4}{|l|}{ Sex } \\
\hline Male & $57.1 \%$ & $13(59.1 \%)$ & $7(46.7 \%)$ \\
\hline Female & $42.9 \%$ & $9(40.9 \%)$ & $8(53.3 \%)$ \\
\hline \multicolumn{4}{|l|}{ Age } \\
\hline Years & $6.6(1.1)$ & $6.5(1.0)$ & $6.7(1.0)$ \\
\hline \multicolumn{4}{|l|}{ Nationality } \\
\hline Dutch & $20(71.4 \%)$ & $15(68.2 \%)$ & $13(86.7 \%)$ \\
\hline Unknown & $8(28.6 \%)$ & $7(31.8 \%)$ & $2(13.3 \%)$ \\
\hline Total IQ & $96.8(15.7)$ & $97.1(17.6)$ & $95.2(9.6)$ \\
\hline \multicolumn{4}{|c|}{ Maternal education level ${ }^{a}$} \\
\hline Low & $5(17.9 \%)$ & $5(22.7 \%)$ & $3(20.0 \%)$ \\
\hline Average & $7(25.0 \%)$ & $4(18.2 \%)$ & $5(33.3 \%)$ \\
\hline High & $6(21.4 \%)$ & $6(27.3 \%)$ & $4(26.7 \%)$ \\
\hline Unknown & $10(35.7 \%)$ & $7(31.8 \%)$ & $3(20.0 \%)$ \\
\hline
\end{tabular}

Note: ${ }^{a}$ Conforms to Dutch classification system (Centraal Bureau voor de Statistiek [Statistics Netherlands], 2017).

Table 2. Participants' primary anxiety disorder diagnoses based on the ADIS-C at preintervention and postintervention

\begin{tabular}{lcc}
\hline Primary anxiety disorder diagnosis & Preintervention, $N(\%)$ & Postintervention, $N(\%)$ \\
\hline Social anxiety disorder & $8(28.57 \%)$ & $4(14.29 \%)$ \\
\hline Specific phobia & $6(21.43 \%)$ & $4(14.29 \%)$ \\
\hline Separation anxiety disorder & $4(14.29 \%)$ & $3(10.71 \%)$ \\
\hline Generalised anxiety disorder & $3(10.71 \%)$ & $1(3.57 \%)$ \\
\hline Selective mutism & $1(3.57 \%)$ & $2(7.14 \%)$ \\
\hline Obsessive compulsive disorder & $2(7.15 \%)$ & $1(3.57 \%)$ \\
\hline No anxiety disorder & $0(0.00 \%)$ & $11(39.3 \%)$ \\
\hline Unknown & $4(14.29 \%)$ & $2(7.14 \%)$ \\
\hline
\end{tabular}

is described in Table 4. During the last 15 minutes of each session, the master's student observed the children during free play, while in a separate room, the psychologists gave the group of parents further information about the home assignments and the exercises performed during the session. The last child session was a booster session in which parents were present and actively involved. All families received a Fun FRIENDS Workbook (Barrett, 2007a; Utens, 2011a), which contained home assignments and additional information about the program.

\section{Measures}

\section{Anxiety Disorders Interview Schedule for Children (ADIS-C)}

The ADIS-C (Siebelink \& Treffers, 2001; Silverman et al., 2001) is a semi-structured interview that was used to assess the presence and severity of DSM-IV anxiety disorders in children and adolescents. The 
Table 3. All anxiety disorder diagnoses based on the ADIS-C at preintervention and postintervention

\begin{tabular}{lcc}
\hline Anxiety disorder diagnosis & Preintervention, $N$ & Postintervention, $N$ \\
\hline Social anxiety disorder & 15 & 10 \\
\hline Specific phobia & 10 & 7 \\
\hline Separation anxiety disorder & 6 & 4 \\
\hline Generalised anxiety disorder & 8 & 2 \\
\hline Selective mutism & 4 & 2 \\
\hline Obsessive compulsive disorder & 4 & 1 \\
\hline No anxiety disorder & 0 & 11 \\
\hline Unknown & 4 & 2 \\
\hline
\end{tabular}

ADIS-C was conducted with parents to assess the following DSM-IV diagnoses: selective mutism, generalised anxiety disorder, social phobia, specific phobia, separation anxiety disorder, panic disorder, agoraphobia, obsessive-compulsive disorder, and posttraumatic stress disorder. For each diagnosis confirmed based on the interview, the parent was asked to rate to what extent the symptoms interfered with the child's daily life on a 9-point scale (i.e., 0-8, higher scores indicating a higher level of interference). Subsequently, the interviewer rated the level of interference on the same 9-point scale, yielding the Clinician Severity Rating (CSR). A CSR of 4 or higher indicates that a DSM-IV diagnosis can be confirmed and assigned. Strong interrater reliability, retest reliability and concurrent validity have been found for the ADIS-C (Lyneham, Abbott, \& Rapee, 2007; Silverman et al., 2001). Preintervention and postintervention interviews were conducted by a different interviewer. All ADIS-C interviews were administered by trained psychologists or trained master's students in psychology. To ensure that all interviewers conducted reliable and valid scoring, the master's students were thoroughly trained by observing live and videotaped interviews. Moreover, they received regular supervision regarding their ADIS-C interviews by their supervising experienced clinical psychologist or psychiatrist, and all ADIS-C interviews were reviewed and discussed in multidisciplinary meetings.

\section{Child Behavior Checklist (CBCL)}

The CBCL 1 1/2-5 (100 items; for 5-year-olds; Achenbach \& Rescorla, 2001) and CBCL/6-18 (120 items; for 6- to 8-year-olds; Achenbach \& Rescorla, 2001) were completed by parents to assess emotional and behavioural problems in children before and after the intervention. Response categories range from 0 to 2, higher scores indicating more problems. The CBCL yields two broadband scales of externalising and internalising behaviours and an overall total score. Furthermore, both the CBCL $1 \frac{1 / 2-5}{2}$ and the CBCL/6-18 encompass the Anxious/Depressed syndrome scale and the $D S M$-oriented Anxiety Problems scale. Adequate psychometric properties have been found (Achenbach et al., 2008).

\section{Statistical Analysis}

First, differences in baseline characteristics between children with complete assessments and children with incomplete assessments were examined using independent samples $t$ tests for continuous data and chi-squared tests or Fisher's exact tests for categorical data.

Second, for the ADIS-C, a Wilcoxon signed-rank test was computed to assess the difference between the number of anxiety disorders at preintervention and postintervention. The difference between average preintervention and postintervention interference scores rated by parents was examined through a paired samples $t$ test. Unfortunately, too many CSRs were missing at preintervention and postintervention to complete statistically warranted reliable analyses on these data. CSRs were 
Table 4. Outline of Fun FRIENDS sessions

\begin{tabular}{|c|c|}
\hline Session & Content of session \\
\hline Session 1 & $\begin{array}{l}\text { - Introduction to the group. } \\
\text { - Development of a positive sense of identity. } \\
\text { - Social skills promotion, 'being brave' (e.g., using a brave voice, making eye contact, smiling). } \\
\text { - Acceptance of differences and similarities between people. }\end{array}$ \\
\hline Session 2 & $\begin{array}{l}\text { F: Feelings } \\
\text { - Identification and recognition of various emotions. } \\
\text { - Understanding feelings in self and others. } \\
\text { - Empathy building, awareness of own emotional responses, and emotion regulation. }\end{array}$ \\
\hline Session 3 & $\begin{array}{l}\text { F: Feelings (continued) } \\
\text { - Coping with emotions; helpful (thumbs up) and unhelpful (thumbs down) behaviours to } \\
\text { regulate feelings. } \\
\text { - Children think of ways to help others when they experience certain emotions. } \\
\text { - The link between emotions and behaviour is discussed. }\end{array}$ \\
\hline Session 4 & $\begin{array}{l}\text { R: Remember to relax } \\
\text { - Identification of physiological arousal ('body clues') related to anxiety. } \\
\text { - Teaching of relaxation strategies to feel more calm and brave (e.g., diaphragmatic breathing, } \\
\text { progressive muscle relaxation, visualisation). }\end{array}$ \\
\hline Session 5 & $\begin{array}{l}\text { I: I can try my best! } \\
\text { - Introduction of cognitive components of the program. } \\
\text { - Identification and awareness of inner thoughts (self-talk), unhelpful (red) and helpful } \\
\text { (green) thoughts. To explain red and green thoughts, the analogy of a traffic light is used. } \\
\text { When we have happy green thoughts, we want to go! When we have unhappy red thoughts, } \\
\text { we want to stop! }\end{array}$ \\
\hline
\end{tabular}

\section{Session $6 \quad$ I: I can try my best! (continued)}

- Challenging 'red' thoughts and changing unhelpful 'red' thoughts into helpful 'green' thoughts.

Session 7

E: Encourage

- The concept of coping step plans is explained. Children are taught how to try new things by breaking tasks down into small steps (graded exposure anxiety hierarchies). Step plans are also explained to parents.

- Focus on friendship skills (e.g., sharing, helping, smiling).

Session $8 \quad$ N: Nurture

- The idea and importance of people who help us achieve our goals (support teams) in different environments is discussed.

Session $9 \quad \begin{aligned} & \text { D: Don't forget to be brave } \\ & \text { - Support teams continued. } \\ & \text { - Planning for difficult (future) situations. }\end{aligned}$

Session $10 \quad$ S: Stay smiling

- Party session: celebration of success in completing the program. Children dress up as their favorite brave person and receive their Fun FRIENDS certificate. Parents are also present.

Session 11 \& $12 \quad$ Booster sessions: review learnt strategies and prepare for future challenges. 
missing due to the retrospective design of the study. As all assessments were conducted as part of regular clinical care, data were not systematically entered into a scientific database. Moreover, changes in digital medical file systems caused logistical difficulties in retrieving a sufficient number of CSRs.

Third, CBCL scores were standardised using $t$ scores as two different versions were used (i.e., CBCL $1 \frac{1}{2}-5$ and CBCL/6-18). Differences between preintervention and postintervention CBCL scores were examined using paired samples $t$ tests.

Finally, it was examined whether sex, age, or preintervention anxiety scores independently predicted treatment progress. Treatment progress was calculated by subtracting postintervention anxiety problem scores on the CBCL from preintervention anxiety problem scores (primary outcome). To examine whether children's sex predicted treatment progress, an independent samples $t$ test was conducted. To examine whether children's age at the start of participation in the Fun FRIENDS program predicted treatment progress, a simple linear regression analysis was performed. Another simple linear regression analysis was performed to examine whether preintervention scores on the anxiety problems subscale of the CBCL predicted treatment progress.

\section{Results}

Mean scores are presented in Table 5. One child missed 6 out of 12 sessions due to logistical reasons, but was included in the analyses according to the intention-to-treat principle. For two children, both the ADIS-C and the CBCL were not fully completed. Therefore, these children were excluded from all analyses.

\section{ADIS-C}

Parents of 22 children completed the ADIS-C at both preintervention and postintervention. Children with complete ADIS-C assessments did not differ from children with incomplete ADIS-C assessments in terms of age, sex, total IQ, and maternal education level (all $p \geq .08$ ).

The mean number of anxiety disorders decreased significantly from preintervention $(M=2.09$, $S D=1.07)$ to postintervention $(M=1.00, S D=1.16), z=-3.04, p=.002$. The effect size was $r=.65$, indicating a large to very large effect (Cohen, 1988). The average interference score rated by parents also significantly decreased from preintervention $(M=1.22, S D=0.77)$ to postintervention $(M=0.63$, $S D=0.78), t(22)=3.34, p=.003$. The effect size was $d=0.76$, indicating a large effect (Cohen, 1988).

\section{$C B C L$}

Unfortunately, the number of CBCLs completed by fathers was too small to analyse. Therefore, only CBCL data reported by mothers were analysed. Mothers of 15 children completed the CBCL at both pre- and postintervention. Children with complete CBCL assessments did not differ from children with incomplete CBCL assessments in terms of age, sex, total IQ, and maternal education level (all $p>.27$ ).

A significant decrease in CBCL total problem scores was found, $t(14)=2.38, p=.032, d=0.34$, which indicates that overall, emotional and behavioural problems decreased from preintervention to postintervention. A significant decrease was also found for internalising problems, $t(14)=2.32, p=.036, d=0.30$, and anxiety problems, $t(14)=2.17, p=.048, d=0.48$. The effect sizes indicate small to medium effects (Cohen, 1988). The observed decrease in scores of the anxious/depressed subscale was not significant, $p=.094, d=0.36$. The decrease in externalising problems was also not significant, $p=.321, d=0.15$.

\section{Predictors of Treatment Progress}

Treatment progress was defined as the difference between preintervention and postintervention CBCL anxiety problems score (primary outcome). A positive score indicates treatment progress (i.e., a lower anxiety problems score at postintervention than at preintervention). 
Table 5. Mean scores for outcome variables and statistical comparisons between preintervention and postintervention

\begin{tabular}{|c|c|c|c|c|}
\hline \multirow[b]{2}{*}{ Measure } & \multicolumn{2}{|c|}{ Mean $(S D)$} & \multirow[b]{2}{*}{$p$ value } & \multirow[b]{2}{*}{ Effect size } \\
\hline & Preintervention & Postintervention & & \\
\hline \multicolumn{5}{|l|}{ ADIS-C $(N=22)$} \\
\hline Number of anxiety disorders ${ }^{a}$ & $2.09(1.07)$ & $1.00(1.16)$ & .002 & $0.65^{c}$ \\
\hline Interference score rated by parents ${ }^{\text {b }}$ & $1.22(0.77)$ & $0.63(0.78)$ & .003 & $0.76^{d}$ \\
\hline \multicolumn{5}{|l|}{ CBCL $t$ scores $^{\ddagger}(N=15)$} \\
\hline Total problem score ${ }^{b}$ & $60.20(9.70)$ & $56.60(11.25)$ & .032 & $0.34^{d}$ \\
\hline Internalising problems ${ }^{\mathrm{b}}$ & $62.27(11.70)$ & $58.87(11.14)$ & .036 & $0.30^{\mathrm{d}}$ \\
\hline Externalising problems ${ }^{\mathrm{b}}$ & $54.07(9.79)$ & $52.47(10.98)$ & .321 & $0.15^{d}$ \\
\hline Anxiety problems ${ }^{b}$ & $66.13(8.99)$ & $62.07(7.97)$ & .048 & $0.48^{d}$ \\
\hline Anxious/depressed ${ }^{\mathrm{b}}$ & $64.60(9.85)$ & $61.33(8.20)$ & .094 & $0.36^{\mathrm{d}}$ \\
\hline
\end{tabular}

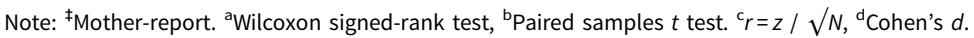

\section{Sex and age}

Treatment progress of boys (mean $\Delta=3.00, S D=7.94$ ) and girls (mean $\Delta=5.00, S D=7.05$ ) did not significantly differ, $p=.614, d=0.27$, indicating that sex does not predict treatment progress. Moreover, children's age at start of participation in Fun FRIENDS did not significantly predict treatment progress, $p=.73$.

\section{Anxiety problems at preintervention}

The level of preintervention anxiety problems did significantly predict treatment progress, $\beta=.537$, $F(1)=5.27, p=.04, R^{2}=.29$. This indicates that a higher preintervention anxiety problems score predicts more treatment progress (demonstrated by a larger positive difference between preintervention and postintervention anxiety problems).

\section{Discussion}

The current study examined whether anxiety in young children with anxiety disorders decreases after participating in the cognitive behavioural Fun FRIENDS program. As expected, we found significant decreases in the number of anxiety disorder diagnoses and symptom interference with young children's daily lives as reported by parents. Moreover, we found significant decreases in emotional and behavioural problems, internalising problems and anxiety problems. These results suggest that the Dutch version of the Fun FRIENDS program is promising in treating anxiety disorders in young children in a clinical setting, which is in line with previous findings (Barrett et al., 2015; Carlyle, 2014). Children with higher levels of preintervention anxiety problems seemed to benefit most from the Fun FRIENDS program, which is also in line with previous findings (Barrett et al., 2015). Sex and age did not predict treatment progress.

The decrease in anxious/depressed symptoms, however, was not significant. This might be surprising, as the Fun FRIENDS program specifically targets issues such as anxiety and depression (Pahl \& Barrett, 2007). Moreover, previous studies have shown that the FRIENDS for Life program (for children aged 8-12 years), on which the Fun FRIENDS program was based, is effective in reducing both anxiety and depressive symptoms (e.g., Ahlen, Breitholtz, Barrett, \& Gallegos, 2012; Essau, Conradt, Sasagawa, \& Ollendick, 2012; World Health Organization, 2004). The difference in results may be explained by the outcome measures used. To measure depressive symptoms, previous studies used the Children's Depression Inventory (CDI; Kovacs, 1985) and the Revised Child Anxiety and 
Depression Scale (RCADS; Chorpita, Yim, Moffitt, Umemoto, \& Francis, 2000), whereas the current study used the CBCL. Moreover, the children who participated in the current study received treatment because they were diagnosed with anxiety disorders. Based on preintervention ADIS-C scores, no children were diagnosed with a depressive disorder at baseline. It should also be noted that, considering the trend towards significance, the decrease in anxious/depressive symptoms may have reached the level of significance if the sample size had been larger.

It is not surprising that externalising problems did not significantly decrease after participating in the Fun FRIENDS program because Fun FRIENDS mainly targets internalising problems (Pahl \& Barrett, 2007). In addition, overall, participants' preintervention externalising problem scores were relatively low and not the main target of treatment. Therefore, a significant decrease in externalising problems might not have been likely.

This study has several strengths. First, it adds to the limited evidence-based knowledge body concerning treatment for young children with clinical levels of anxiety. Second, this is the first European study examining the Fun FRIENDS program. It is important to cross-validate findings across countries using the same validated assessment instruments and protocols. This enables us to draw more robust conclusions as to outcomes after participating in the Fun FRIENDS program. Third, the senior psychologist providing the Fun FRIENDS program was trained by the program developer; and, fourth, treatment was fully manualised and standardised.

However, although promising, the results of the current study should be interpreted with caution as the study did not include a control group, which limits the internal validity (Shadish, Cook, \& Campbell, 2002). In this study, internal validity refers to whether the decline in symptoms can be attributed to participating in the Fun FRIENDS program. Without the use of a control group, it is not possible to draw definite conclusions as to the effectiveness of an intervention, because other influences on the outcome cannot be ruled out. For example, the decline in symptoms may also be influenced by maturation (i.e., naturally occurring changes over time) or regression to the mean (i.e., the tendency to score less extremely on a posttest assessment than on a pretest assessment). In the future, randomised controlled trials with larger groups of participants should be conducted in order to draw definite conclusions as to the effectiveness of the Fun FRIENDS program. It would also be useful to include a long-term follow-up assessment to examine whether the obtained results remain over a longer period of time.

Moreover, to optimise treatment for young children with anxiety disorders, future research should focus on which elements of the Fun FRIENDS program are most useful. Future research could also consider the format in which the intervention is delivered. A randomised controlled trial has shown that the FRIENDS for Life program (Barrett \& Turner, 2000; translated by Utens, de Nijs, \& Ferdinand, 2001) is as equally effective in diminishing anxiety through individual treatment as through group treatment (Liber et al., 2008). Whether this also holds true for the Fun FRIENDS program should be examined in future research. The psychologists, parents and children involved in the current study considered the group format to be beneficial. The group format seemed to enable children to learn from each other and to encourage each other in learning the cognitive behavioural techniques. However, when delivering an intervention in a group format, children may drop out due to different issues (e.g., change in parents' working schedule), which may also have a negative influence on the rest of the group. For this reason, prior to participating in the program, we asked parents to fully commit to the treatment.

In conclusion, the Fun FRIENDS program is one of the very few cognitive behavioural treatment programs for young children with anxiety disorders. The current study shows promising results as to the outcomes after participating in the Fun FRIENDS program. To determine the effectiveness of the program in a clinical setting, randomised controlled trials with longer follow-up periods are needed.

Acknowledgments. This research received no specific grant from any funding agency, commercial or not-for-profit sectors.

Declaration of interest. The authors declare that they have no conflict of interest. EU translated the FRIENDS for Life and Fun FRIENDS manuals to Dutch but does not receive remuneration for this. 
Ethical standards. The authors assert that all procedures contributing to this work comply with the ethical standards of the relevant national and institutional committees on human experimentation and with the Helsinki Declaration of 1975, as revised in 2008 .

\section{References}

Achenbach TM, Becker A, Dopfner M, Heiervang E, Roessner V, Steinhausen HC and Rothenberger A (2008). Multicultural assessment of child and adolescent psychopathology with ASEBA and SDQ instruments: Research findings, applications, and future directions. Journal of Child Psychology and Psychiatry, 49, 251-275.

Achenbach TM and Rescorla LA (2001). Manual for the ASEBA School-Age Forms \& Profiles. Burlington, VT: University of Vermont, Research Center for Children, Youth, \& Families.

Ahlen J, Breitholtz E, Barrett PM and Gallegos J (2012). School-based prevention of anxiety and depression: A pilot study in Sweden. Advances in School Mental Health Promotion, 5, 246-257.

Albano AM, Chorpita BF and Barlow DH (2003). Child psychopathology. In EJ Mash \& RA Barkley (Eds), Childhood anxiety disorders (pp. 279-329). New York, NY: Guilford Press.

American Psychiatric Association. (1994). Diagnostic and statistical manual of mental disorders (4th ed.). Washington, DC: Author.

Anticich SAJ, Barrett PM, Silverman W, Lacherez P and Gillies R (2013). The prevention of childhood anxiety and promotion of resilience among preschool-aged children: A universal school based trial. Advances in School Mental Health Promotion, 6, 93-121.

Ashdown DM and Bernard ME (2011). Can explicit instruction in social and emotional learning skills benefit the social-emotional development, well-being, and academic achievement of young children? Early Childhood Education Journal, 39, 397-405.

Barrett PM (2007a). Fun FRIENDS: Family learning adventure: Resilience building activities for 4-, 5-, and 6-year-old children. Brisbane, Australia: Fun Friends Publishing.

Barrett PM (2007b). Fun FRIENDS: The teaching and training manual for group leaders. Brisbane, Australia: Fun FRIENDS Publishing.

Barrett PM (2012a). Strong Not Tough Adult Program: Resilience Throughout Life (2nd ed.). Brisbane, Australia: Pathways Health and Research Centre.

Barrett PM (2012b). Strong Not Tough Adult Program: Resilience Throughout Life: Guidelines for facilitators (2nd ed.). Brisbane, Australia: Pathways Health and Research Centre.

Barrett PM, Cooper M and Teoh ABH (2014). When time is of the essence: A rationale for 'earlier' early intervention. Journal of Psychological Abnormalities in Children, 3, 133-140.

Barrett P, Fisak B and Cooper M (2015). The treatment of anxiety in young children: Results of an open trial of the Fun FRIENDS program. Behaviour Change, 32, 231-242.

Barrett PM and Turner C (2000). Friends for Children: Group leader's manual. Brisbane Hills, Australia: Australian Academic Press.

Bienvenu OJ and Ginsburg GS (2007). Prevention of anxiety disorders. International Review of Psychiatry, 19, 647-654.

Bittner A, Egger HL, Erkanli A, Costello JE, Foley DL and Angold A (2007). What do childhood anxiety disorders predict? Journal of Child Psychology and Psychiatry, 48, 1174-1183.

Bodden DH, Dirksen CD and Bögels SM (2008). Societal burden of clinically anxious youth referred for treatment: A cost-of-illness study. Journal of Abnormal Child Psychology, 36, 487-497.

Carlyle DA (2014). With a little help from FUN FRIENDS young children can overcome anxiety. Journal of Community Practice, 87, 26-29.

Centraal Bureau voor de Statistiek (Statistics Netherlands) (2017). Standaard onderwijsindeling: Editie 2016/'17. Den Haag/ Heerlen, the Netherlands: CBS

Chorpita BF, Yim L, Moffitt C, Umemoto LA and Francis SE (2000). Assessment of symptoms of DSM-IV anxiety and depression in children: A revised child anxiety and depression scale. Behaviour Research and Therapy, 38, 835-855.

Cohen J (1988). Statistical power analysis for the behavioral sciences (2nd ed.). New York, NY: Lawrence Erlbaum Associates.

Connolly SD and Bernstein GA (2007). Practice parameter for the assessment and treatment of children and adolescents with anxiety disorders. Journal of the American Academy of Child and Adolescent Psychiatry, 46, 267-283.

Copeland WE, Adair CE, Smetanin P, Stiff D, Briante C, Colman I ... Angold A (2013). Diagnostic transitions from childhood to adolescence to early adulthood. Journal of Child Psychology and Psychiatry, 54, 791-799.

Copeland WE, Shanahan L, Costello J and Angold A (2009). Childhood and adolescent psychiatric disorders as predictors of young adult disorders. Archives of General Psychiatry, 66, 764-772.

Costello EJ, Mustillo S, Erkanli A, Keeler G and Angold A (2003). Prevalence and development of psychiatric disorders in childhood and adolescence. Archives of General Psychiatry, 60, 837-844.

de Lijster JM, Dieleman GC, Utens E, Dierckx B, Wierenga M, Verhulst FC and Legerstee JS (2018). Social and academic functioning in adolescents with anxiety disorders: A systematic review. Journal of Affective Disorders, 230, 108-117. 
Donovan CL and March S (2014). Online CBT for preschool anxiety disorders: A randomised control trial. Behaviour Research and Therapy, 58, 24-35.

Egger HL and Angold A (2006). Common emotional and behavioral disorders in preschool children: Presentation, nosology, and epidemiology. Journal of Child Psychology and Psychiatry, 47, 313-337.

Essau CA, Conradt J, Sasagawa S and Ollendick TH (2012). Prevention of anxiety symptoms in children: Results from a universal school-based trial. Behavior Therapy, 43, 450-464.

Essau CA, Lewinsohn PM, Lim JX, Ho MR and Rohde P (2018). Incidence, recurrence and comorbidity of anxiety disorders in four major developmental stages. Journal of Affective Disorders, 228, 248-253.

Essau CA, Lewinsohn PM, Olaya B and Seeley JR (2014). Anxiety disorders in adolescents and psychosocial outcomes at age 30. Journal of Affective Disorders, 163, 125-132.

Fisak B and Barrett P (2019). Anxiety in preschool children: Assessment, treatment, and prevention. New York, NY: Routledge.

Fisak B, Gallegos-Guajardo J, Verreynne $\mathbf{M}$ and Barrett $\mathbf{P}$ (2018). The results of a targeted open trial of the Fun FRIENDS combined with a concurrent parent-based intervention. Mental Health \& Prevention, 10, 35-41.

Fox JK, Warner CM, Lerner AB, Ludwig K, Ryan JL, Colognori D ... Brotman LM (2012). Preventive intervention for anxious preschoolers and their parents: Strengthening early emotional development. Child Psychiatry \& Human Development, 43, 544-559.

Hirshfeld-Becker DR and Biederman J (2002). Rationale and principles for early intervention with young children at risk for anxiety disorders. Clinical Child and Family Psychology Review, 5, 161-172.

Kendall PC (1994). Treating anxiety disorders in children: Results of a randomized clinical trial. Journal of Consulting and Clinical Psychology, 62, 100-110.

Kovacs M (1985). The Children's Depression Inventory (CDI). Psychopharmacology Bulletin, 21, 995-998.

Liber JM, Van Widenfelt BM, Utens EMWJ, Ferdinand RF, Van der Leeden AJM, Van Gastel W and Treffers PDA (2008). No differences between group versus individual treatment of childhood anxiety disorders in a randomised clinical trial. Journal of Child Psychology and Psychiatry, 49, 886-893.

Lyneham HJ, Abbott MJ and Rapee RM (2007). Interrater reliability of the Anxiety Disorders Interview Schedule for DSM-IV: Child and parent version. Journal of the American Academy of Child and Adolescent Psychiatry, 46, 731-736.

McLaughlin KA, Breslau J, Green JG, Lakoma MD, Sampson NA, Zaslavsky AM and Kessler RC (2011). Childhood socioeconomic status and the onset, persistence, and severity of DSM-IV mental disorders in a US national sample. Social Science \& Medicine, 73, 1088-1096.

Mian ND, Godoy L, Briggs-Gowan MJ and Carter AS (2012). Patterns of anxiety symptoms in toddlers and preschool-age children: evidence of early differentiation. Journal of Anxiety Disorders, 26, 102-110.

Moffitt TE, Caspi A, Harrington H, Milne BJ, Melchior M, Goldberg D and Poulton R (2007). Generalized anxiety disorder and depression: Childhood risk factors in a birth cohort followed to age 32. Psychological Medicine, 37, 441-452.

Mychailyszyn MP, Mendez JL and Kendall PC (2010). School functioning in youth with and without anxiety disorders: Comparisons by diagnosis and comorbidity. School Psychology Review, 39, 106-121.

Pahl KM and Barrett PM (2007). The development of social-emotional competence in preschool-aged children: An introduction to the Fun FRIENDS program. Australian Journal of Guidance \& Counselling, 17, 81-90.

Pahl KM and Barrett PM (2010). Preventing anxiety and promoting social and emotional strength in preschool children: A universal evaluation of the Fun FRIENDS program. Advances in School Mental Health Promotion, 3, 14-25.

Paulus FW, Backes A, Sander CS, Weber M and von Gontard A (2015). Anxiety disorders and behavioral inhibition in preschool children: A population-based study. Child Psychiatry \& Human Development, 46, 150-157.

Siebelink BM and Treffers PDA (2001). Anxiety Disorder Interview Schedule for DSM-IV Child Version/Dutch Translation. Lisse, the Netherlands: SWETS Test Publishers.

Silverman WK, Saavedra LM and Pina AA (2001). Test-retest reliability of anxiety symptoms and diagnoses with the Anxiety Disorders Interview Schedule for DSM-IV: Child and parent versions. Journal of the American Academy of Child and Adolescent Psychiatry, 40, 937-944.

Shadish W, Cook TD and Campbell DT (2002). Experimental and quasi-experimental designs for generalized causal inference. Boston, MA: Houghton Mifflin.

Towe-Goodman NR, Franz L, Copeland W, Angold A and Egger H (2014). Perceived family impact of preschool anxiety disorders. Journal of the American Academy of Child and Adolescent Psychiatry, 53, 437-446.

Utens EMWJ (2011a). FIJN: VRIENDEN! Handleiding voor ouders om emotionele veerkracht door middel van spel op te bouwen bij 4 tot en met 7 jarigen. Rotterdam, the Netherlands: Erasmus MC - Sophia Kinderziekenhuis.

Utens EMWJ (2011b). FIJN: VRIENDEN! Handleiding voor trainers om emotionele veerkracht door middel van spel op te bouwen bij 4 tot en met 7 jarigen. Rotterdam, the Netherlands: Erasmus MC - Sophia Kinderziekenhuis.

Utens EMWJ, de Nijs P and Ferdinand RF (2001). FRIENDS for children - manual for group leaders (Dutch translation). Rotterdam, the Netherlands: Department of Child and Adolescent Psychiatry Erasmus Medical Centre - Sophia Children's Hospital. 
von Klitzing K, Dohnert M, Kroll M and Grube M (2015). Mental disorders in early childhood. Deutsches Ärzteblatt International, 112, 375-386.

World Health Organization (2004). Prevention of mental disorders: Effective interventions and policy options. Geneva, Switzerland: Author.

Cite this article: van der Mheen M, Legerstee JS, Dieleman GC, Hillegers MHJ, Utens EMWJ (2020). Cognitive Behavioural Therapy for Anxiety Disorders in Young Children: A Dutch Open Trial of the Fun FRIENDS Program. Behaviour Change 37, 1-12. https://doi.org/10.1017/bec.2019.16 